\title{
Identification of iron-loaded ferritin as an essential mitogen for cell proliferation and postembryonic development in Drosophila
}

\author{
Sheng $\mathrm{Li}^{1,2}$ \\ ${ }^{I}$ Key Laboratory of Insect Developmental and Evolutionary Biology, Institute of Plant Physiology and Ecology, Shanghai Institutes \\ for Biological Sciences, Chinese Academy of Sciences, Shanghai 200032, China; ${ }^{2}$ Department of Molecular Biology and Genetics, \\ Howard Hughes Medical Institute, Johns Hopkins University School of Medicine, Baltimore, MD 21205, USA
}

\begin{abstract}
Animal cells require extrinsic cues for growth, proliferation and survival. The propagation of Drosophila imaginal disc cells in vitro, for example, requires the supplementation of fly extract, the composition of which remains largely undefined. Here I report the biochemical purification of iron-loaded ferritin as an active ingredient of fly extract that is required for promoting the growth of clone 8 imaginal disc cells. Consistent with an essential role for ironloaded ferritin in cultured cells, overexpression of ferritin or addition of iron in a nutrient-poor diet increases animal viability and body weight, promotes cell proliferation, and shortens the duration of postembryonic development. Conversely, overexpression of dominant-negative ferritin or addition of iron chelator causes the opposite effects. Ferritin mutant flies arrest development at the first-instar larval stage with a severe starvation phenotype reminiscent of that seen in starved larvae. I conclude that iron-loaded ferritin acts as an essential mitogen for cell proliferation and postembryonic development in Drosophila by maintaining iron homeostasis and antagonizing starvation response.
\end{abstract}

Keywords: ferritin; apoferritin; iron; mitogen; $\mathrm{Cl} 8$ cell; starvation; Drosophila melanogaster

Cell Research (2010) 20:1148-1157. doi:10.1038/cr.2010.102; published online 13 July 2010

\section{Introduction}

Animal cells require extracellular signals for growth, proliferation and survival. These extracellular cues may be classified into several distinct groups, including growth factors, hormones, neuropeptides, morphogens, and nutrients such as amino acids and essential metals [1, 2]. A challenge is to define the complete repertoire of extrinsic cues that are required for the growth of a specific cell or organ type.

The imaginal discs of Drosophila melanogaster have served as a powerful model to study growth control in a physiological setting. Originated from embryonic primordia of 20-50 cells, the imaginal disc grows exponentially in the larval stages and increases its cell number

Correspondence: Sheng $\mathrm{Li}$

Tel: +86-21-54924163; Fax: +86-21-54924163

E-mail: shengli@sippe.ac.cn

Received 7 March 2010; revised 20 April 2010; accepted 21 April 2010; published online 13 July 2010 by about 1000 -fold before terminal differentiation [3, 4]. Genetic studies in the past decades have implicated a variety of extrinsic factors in controlling imaginal disc growth in vivo, among which are the epidermal growth factor [5], the insulin-like peptides [6], and secreted morphogens such as decapentaplegic, hedgehog, and wingless [7].

Cultured Drosophila cell lines have provided an alternative model to identify and characterize novel extrinsic factors that are required for cell growth. Continuous cell lines have been successfully established from Drosophila embryos, as well as the blood, the imaginal discs, or the nervous system of late third instar larvae [8]. Unlike other cell lines, propagation of all cell lines derived from the imaginal discs, including the most commonly used cell line clone $8(\mathrm{Cl} 8)$, requires the addition of extract prepared from adult flies or pupae to the culture medium [9]. The unknown growth-promoting factors in the fly extract appear to be proteins, since they are not removed by dialysis and are considerably inhibited by heating. They cannot be insulin since insulin is already present in 
the culture medium [10].

Two families of polypeptide growth factors, imaginal disc growth factors (IDGFs) [11] and adenosine deaminase-related growth factors (ADGFs) [12], have been reported to have stimulatory effects on $\mathrm{Cl} 8$ cell growth. IDGFs were purified from the conditioned medium of $\mathrm{Cl} 8$ cells as proteins that stimulate $\mathrm{Cl} 8$ cell growth in cooperation with insulin. They encode a family of chitinase-like proteins lacking enzyme activity due to mutation of a critical catalytic residue [11]. Drosophila ADGFs were identified based on sequence homology to a mitogenic growth factor discovered in the conditioned medium of cells of a different fly species, Sarcophaga. Recombinant ADGFs are active adenosine deaminases and stimulate serum-independent proliferation of $\mathrm{Cl} 8$ cells in vitro. It is believed that ADGFs secreted in vivo may control tissue growth by modulating the level of extracellular adenosine [12].

Although IDGFs and ADGFs appear to have a mitogenic effect on $\mathrm{Cl} 8$ cells, neither was originally identified from fly extract. In this study, I used protein chromatography to purify the growth factor(s) from fly extract that are required for the proliferation of $\mathrm{Cl} 8$ cells in vitro. My results demonstrate that iron-loaded ferritin is an essential mitogen for $\mathrm{Cl} 8$ cell proliferation. Furthermore, I show that iron-loaded ferritin regulates Drosophila postembryonic development by maintaining iron homeostasis and antagonizing starvation response.

\section{Results}

\section{Characterization of Cl8 growth factors in fly extract}

As a starting point for purification, I characterized the biochemical properties of the $\mathrm{Cl} 8$ growth factor(s) in fly extracts. $\mathrm{Cl} 8$ cells are commonly grown by supplementing an incomplete medium (IM), which contains Shields and Sang's M3 medium, 2\% inactivated fetal bovine serum, $0.125 \mathrm{IU} / \mathrm{ml}$ insulin and antibiotics, with fly extract at $2.5 \%$ [9]. The growth-promoting activity of fly extract can be measured by measuring the fold increase in cell number with versus without fly extract after 4 days of incubation (Supplementary information, Figure S1A). Under such assay condition, I found that the $\mathrm{Cl} 8$ growth factor activity was stable at $60{ }^{\circ} \mathrm{C}$ but disappeared after treatment at $95{ }^{\circ} \mathrm{C}$. Treatments of fly extract with acid or protease decreased this activity to undetectable levels. Furthermore, this activity was retained by Centricon Ultracel membrane with a $10-\mathrm{kDa}$ molecular weight cutoff. Thus, the $\mathrm{Cl} 8$ growth factor(s) in fly extract appears to be a protein(s) (Supplementary information, Figure S1B).

The growth-promoting activity of fly extract is dose- dependent when supplemented in the concentration range of $0-2.5 \%$ and reaches a maximum at $2.5 \%$ (Supplementary information, Figure S1B and S1C). No significant difference was observed between the fly extracts prepared from adult females and males. Interestingly, the extract prepared from adult flies showed higher growthpromoting activity than that prepared from embryos, larvae or pupae, suggesting that this activity varies in different developmental stages (Supplementary information, Figure S1C).

\section{Identification of ferritin as a Cl8 growth factor}

The $\mathrm{Cl} 8$ growth factor was purified by fast protein liquid chromatography (FPLC) using the scheme shown in Figure $1 \mathrm{~A}$. The crude fly extract was first subjected to $60^{\circ} \mathrm{C}$ heat inactivation, which retained the growth-promoting activity but efficiently removed the bulk of proteins in fly homogenate (Figure 1B, lanes 1-4). The resulting protein extract was first separated using the strong-anion exchange column HiTrap Q XL (Figure 1B, lanes 5-7), which removed $\sim 80 \%$ of total proteins but retained $\sim 85 \%$ of total $\mathrm{Cl} 8$ growth factor activity (Figure 1C). The active fractions from HiTrap Q XL were further separated by the strong cation-exchange column HiTrap SP XL (Figure $1 \mathrm{~B}$, lane $8 ; \sim 30 \%$ of protein left) or the gel filtration column Superdex 200 HR 10/30 (Figure 1B, lane 9; 30\% of protein left). After either step of separation, the active fractions contained two major bands at $\sim 25$ and $\sim 23-\mathrm{kDa}$. Interestingly, all the active fractions showed a color from yellow to dark red depending on the protein concentration and a major absorption peak at $400-450 \mathrm{~nm}$, indicative of the presence of chromophores in these proteins. I further estimated the molecular weight of the $\mathrm{Cl} 8$ growth factor from fly extract to be $\sim 600 \mathrm{kDa}$ by comparing the elution of the active fractions to the protein molecular weight standard in gel filtration chromatography (Figure 1D), suggesting that the active $\mathrm{Cl} 8$ growth factor may be a multimer of the $\sim 25$ and $\sim 23-\mathrm{kDa}$ proteins. Overall, my results indicate that the $\mathrm{Cl} 8$ growth factor is a major constituent of the fly extract, representing $\sim 0.8 \%$ of the total protein.

Mass spectrometry analysis revealed that the $\sim 25$ and $\sim 23-\mathrm{kDa}$ bands correspond to Ferritin 2 light chain homologue (Fer2LCH) and Ferritin 1 heavy chain homologue (Fer1HCH), respectively. Drosophila ferritin is a large $(>600 \mathrm{kDa})$ protein consisting of 24 subunits of Fer1HCH and Fer2LCH as well as an iron core [13]. I note that the molecular weight of Drosophila ferritin is consistent with the estimated size of the $\mathrm{Cl} 8$ growth factor based on gel filtration analysis (Figure 1D), suggesting that ferritin is indeed the $\mathrm{Cl} 8$ growth factor I was looking for. 
A

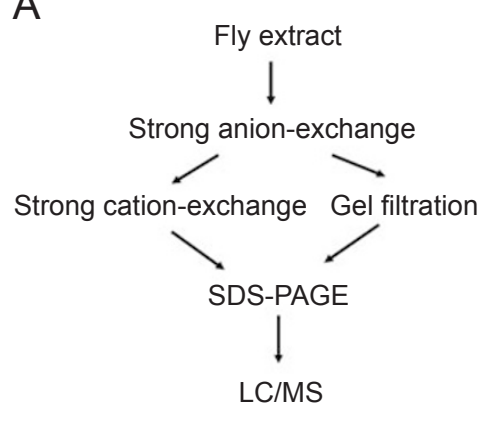

B

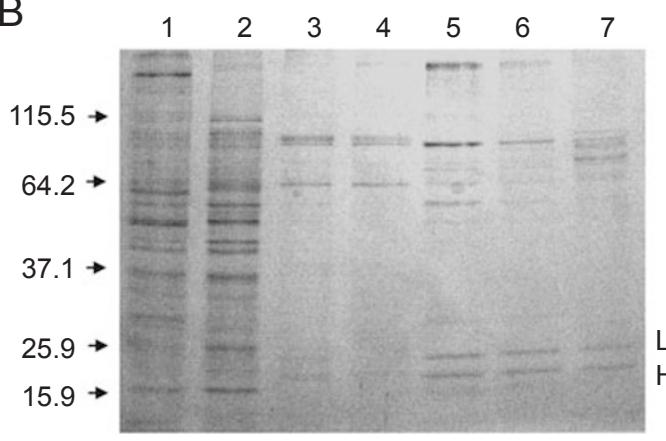

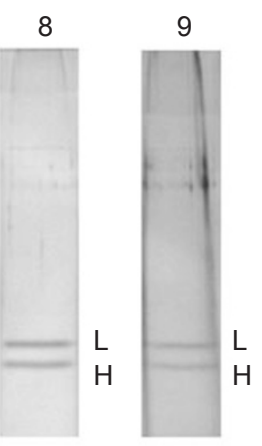

C
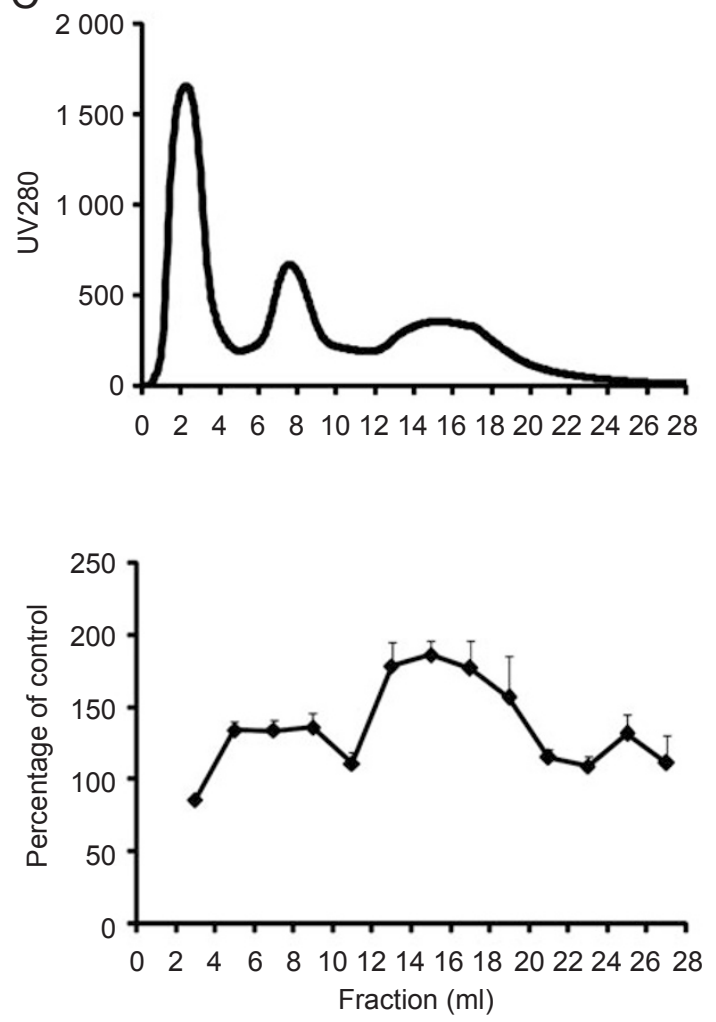
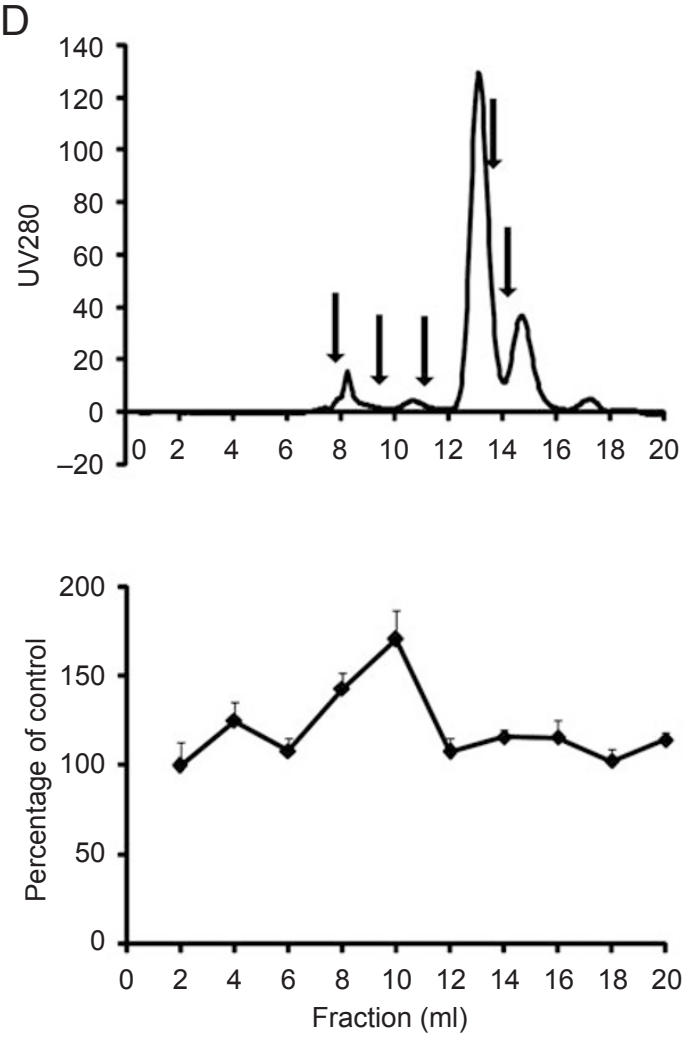

Figure 1 Identification of the $\mathrm{Cl} 8$ growth factor as iron-loaded ferritin. (A) Purification scheme for the identification $\mathrm{Cl} 8$ growth factor. (B) SDS-PAGE analysis fractions containing Cl8 growth factor activity. Lanes 1-7, Collodial blue staining: lane 1, crude fly homogenate; lane 2, supernatant from the crude fly homogenate after centrifugation at $20000 \times \mathrm{g}$; lane 3 , supernatant after $60{ }^{\circ} \mathrm{C}$ inactivation followed by centrifugation at $20000 \times \mathrm{g}$; lane 4 , lane 3 sample after ultracentrifugation at $200000 \times \mathrm{g}$; lanes 5-7, fractions $12+13,14+15$, and 16+17 from the strong anion-exchange (HiTrap Q XL) chromatography. Lanes 8 and 9, silver staining: lane 8, active fractions from the strong cation-exchange (HiTrap SP XL) chromatography; lane 9, active fractions from the gel filtration (Superdex $200 \mathrm{HR}$ 10/30) chromatography. Fer1HCH (abbreviated as H) and Fer2LCH (abbreviated as $\mathrm{L}$ ) are marked at the right side of each gel. (C) FPLC purification of the Cl8 growth factor from fly extract by a strong anion-exchange (HiTrap Q XL) chromatography. Upper: elution profile of the FPLC fractions; bottom: Cl8 growth factor activity of the FPLC fractions. The $\mathrm{Cl} 8$ growth factor activity was calculated as percentage of control (cell number after 4 days of incubation with/without fraction $\times 100$, mean $\pm \mathrm{SEM}, n=4$ ). (D) Estimation of the molecular weight of the Cl8 growth factor from fly extract using gel filtration (Superdex 200 HR 10/30 column) chromatography. Upper: elution profile of the FPLC fractions; bottom: $\mathrm{Cl} 8$ growth factor activity of the FPLC fractions. From the left to the right, arrows point to the elution time of the molecular weight standards used: thyroglobulin $(669 \mathrm{kDa})$, apoferritin (443 kDa), $\beta$-amylase (200 kDa), BSA (66 kDa), and ovalbumin (45 kDa). 
Iron-loaded ferritin stimulates Cl8 cell proliferation

To confirm that ferritin is a $\mathrm{Cl} 8$ growth factor, I tested the effect of purified ferritin on $\mathrm{Cl} 8$ cell proliferation. Ferritin exists either as iron-loaded holoferritin or ironstripped apoferritin [14]. I found that in the absence of fly extract, purified holoferritin (from horse spleen) stimulated $\mathrm{Cl} 8$ cell proliferation in a dose-dependent manner (Figure 2A). In contrast, purified apoferritin (from horse spleen) did not stimulate $\mathrm{Cl} 8$ cell proliferation (Figure 2B). Thus, holoferritin, but not apoferritin, functions as a $\mathrm{Cl} 8$ growth factor. I also tested another iron-carrying protein, the human transferrin, and observed no effects on $\mathrm{Cl} 8$ cell proliferation (Supplementary information, Figure S1D).

It is well known that iron is an essential cofactor for many proteins, and that the iron-binding proteins ferritin and transferrin play a critical role in maintaining iron homeostasis [14]. Since iron overload is known to induce ferritin expression in Drosophila $[15,16]$, I tested the effect of supplementing iron on $\mathrm{Cl} 8$ cell proliferation, in the absence of fly extract supplementation. Strikingly, $\mathrm{FeCl}_{3}$ alone stimulated $\mathrm{Cl} 8$ cell proliferation in a dosedependent manner in the $0-12.5 \mu \mathrm{g} / \mathrm{ml}$ range, but its stimulating effect steadily decreased at concentrations $>12.5 \mu \mathrm{g} / \mathrm{ml}$ (Figure 2C). In addition, ammonium iron (III) citrate had similar stimulatory effects on $\mathrm{Cl} 8$ cell proliferation to $\mathrm{FeCl}_{3}$ (Supplementary information, Figure $\mathrm{S} 1 \mathrm{E}$ ). Neither apoferritin (Figure 2B) nor $0.75 \mu \mathrm{g} / \mathrm{ml}$ of $\mathrm{FeCl}_{3}$ stimulated the growth of $\mathrm{Cl} 8$ cells (Figure 2D). As iron can be incorporated into apoferritin [15], simultaneous addition of $0.75 \mu \mathrm{g} / \mathrm{ml} \mathrm{FeCl}_{3}$ and apoferritin showed significant growth-promoting activity (Figure 2D), fur-
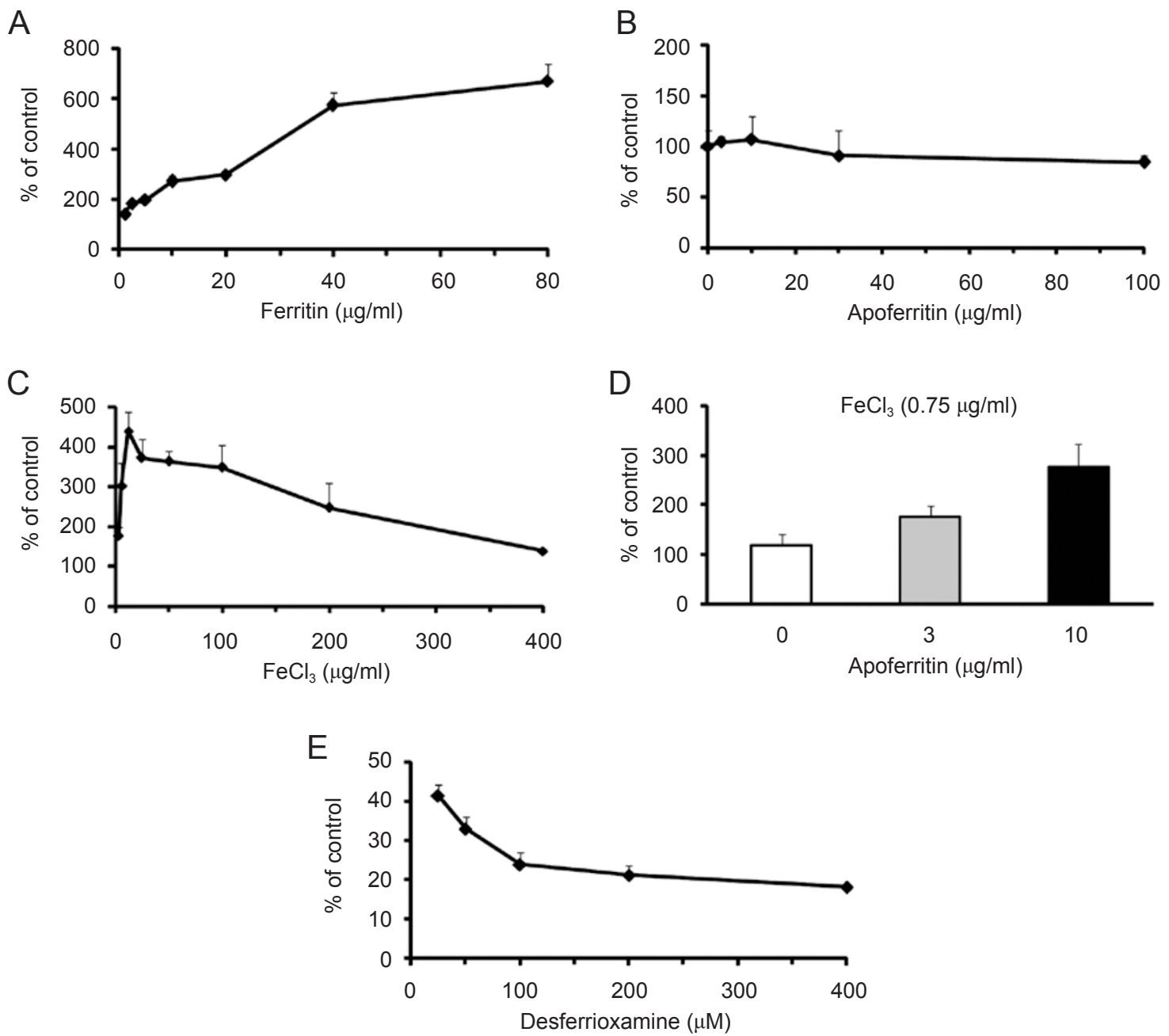

Figure 2 Ferritin stimulates $\mathrm{Cl} 8$ cell proliferation. Effects of various concentrations of ferritin (A), apoferritin (B), $\mathrm{FeCl}_{3}(\mathbf{C})$, apoferritin with $0.75 \mu \mathrm{g} / \mathrm{ml} \mathrm{FeCl}_{3}(\mathrm{D})$, and desferrioxamine (E) on Cl8 cell proliferation. The Cl8 growth factor activity was calculated as percentage of control (= cell number after 4 days of incubation with/without supplements $\times 100$, mean \pm SEM, $n=4$ ). 

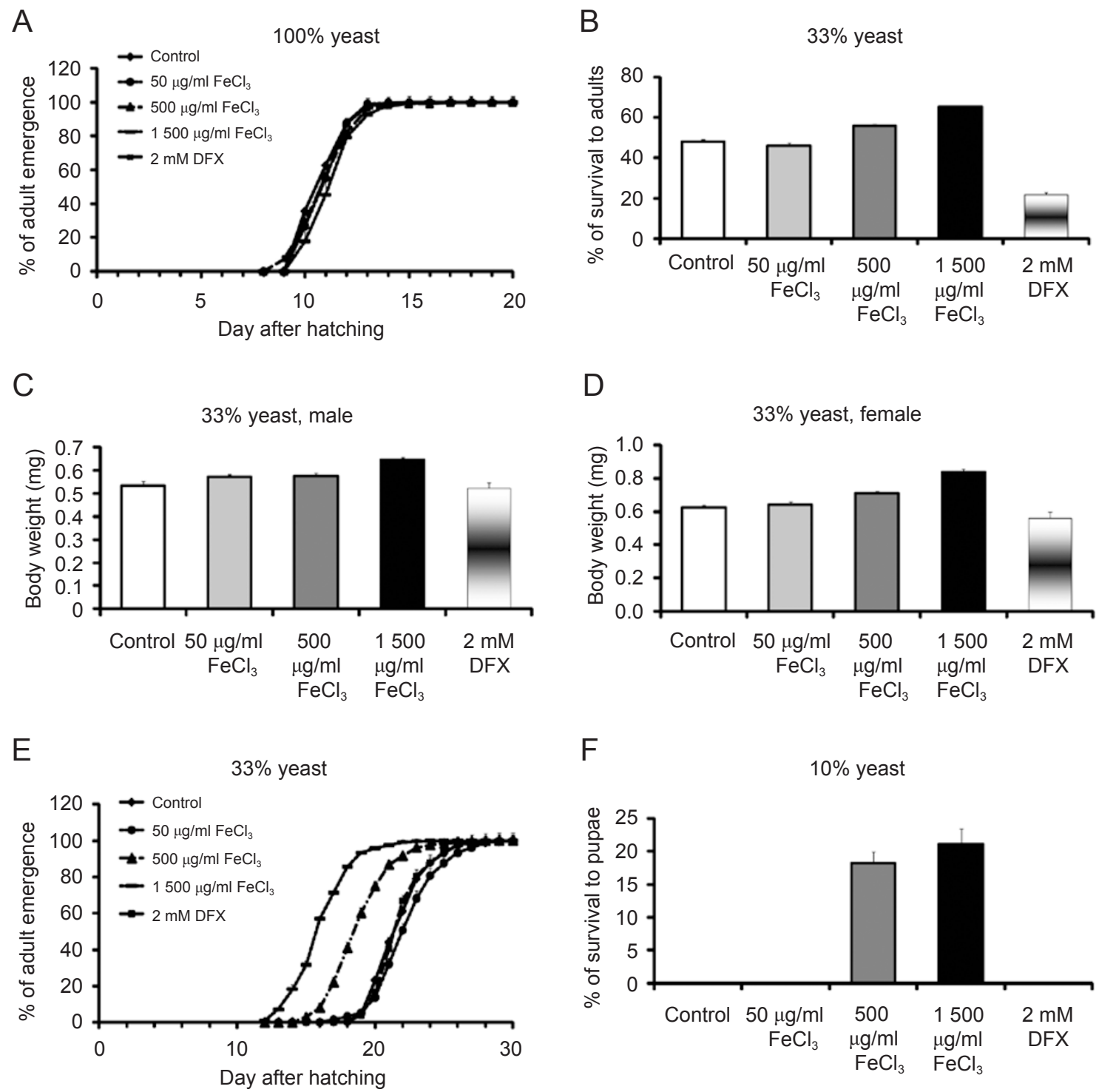

Figure 3 Iron stimulates Drosophila postembryonic development in nutrient-poor diets. (A) Effects of FeCl 3 and desferrioxamine (DFX) on the period for adult emergence in a normal diet. $\mathrm{AE}_{50}$ represents the time point with $50 \%$ of adult emergence. (B) Effects of $\mathrm{FeCl}_{3}$ and DFX on the percentage of flies surviving to adults in a diet with $33 \%$ yeast. (C, D) Effects of $\mathrm{FeCl}_{3}$ and DFX on the body weight of male (D) and female (E) flies in a diet with $33 \%$ yeast. Body weight was measured 2 days after eclosion. (E) Effects of $\mathrm{FeCl}_{3}$ and DFX on the period for adult emergence in a diet with $33 \%$ yeast. (F) Effects of $\mathrm{FeCl}$ and DFX on viability in a diet with $10 \%$ yeast.

ther supporting the notion that iron-loaded ferritin is a $\mathrm{Cl} 8$ growth factor. Consistent with a stimulatory role for iron-loaded ferritin in $\mathrm{Cl} 8$ cell proliferation, addition of the iron chelator desferrioxamine decreased the cell number (Figure 2E). Taken together, I conclude that ironloaded ferritin is a growth factor for $\mathrm{Cl} 8$ cells.

Ferritin stimulates Drosophila postembryonic development in nutrient-poor diets

Having established a growth-promoting role for fer- ritin in cultured cells, I explored the function of ferritin in intact flies. In the following experiments, I used iron overload or overexpression of ferritin subunits to artificially increase ferritin activity. Conversely, I used iron chelator or overexpression of dominant-negative ferritins to decrease ferritin activity.

Addition of different concentrations of $\mathrm{FeCl}_{3}$ or the iron chelator desferrioxamine caused no significant effect on viability, body weight, or duration of postembryonic development (i.e., the time period from hatching to adult 
emergence) when the animals were grown in a normal diet (Figure 3A). Interestingly, when flies were grown in a nutrient-poor diet containing only $33 \%$ of yeast present in a normal diet, iron addition showed a dose-dependent stimulating effect on Drosophila postembryonic development. For example, addition of $1500 \mu \mathrm{g} / \mathrm{ml} \mathrm{FeCl}_{3}$ led to improved viability (by $\sim 40 \%$ ) (Figure $3 \mathrm{~B}$ ), increased body weight (by $\sim 20 \%$ for males and $\sim 35 \%$ for females) (Figure 3C and 3D), and shortened period for adult emergence ( $\sim 6$ days, or $\sim 30 \%$ ) (Figure $3 \mathrm{E}$ ). Conversely, addition of $2 \mathrm{mM}$ of desferrioxamine led to a decrease in viability (by $\sim 55 \%$ ) (Figure $3 \mathrm{~B}$ ) and the body weight of females (by $\sim 10 \%$ ) (Figure 3D), although it had no significant effect on the body weight of males (Figure 3C) or on the duration of postembryonic development (Figure $3 \mathrm{E})$. I then measured if iron addition had any effects on cell proliferation. It appeared that iron addition had little effects on mitotic cells, including imaginal disc cells and neuroblasts (data not shown), but greatly improved endoreplicative cycles in fat body and midgut cells. At $36 \mathrm{~h}$ after hatching, with or without iron addition in the nutrient-poor diet, all the larvae still remained at the $1^{\text {st }}$ instar and their body weights were similar. However, compared to fat body (Figure 4A) and midgut (Figure 4C) cells in the control larvae, addition of iron significantly increased cell sizes and promoted BrdU incorporation per cell in these tissues (Figure 4B and 4D). I further tested the ef-
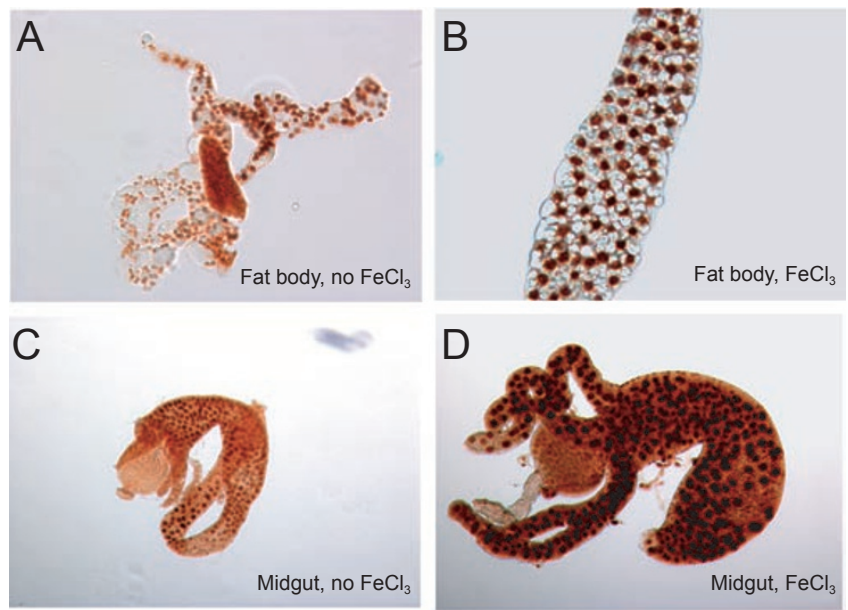

Figure 4 Iron stimulates cell proliferation of fat body and midgut of Drosophila larvae in nutrient-poor diets. (A, B) Fat body cells of Drosophila larvae reared in the fly diet with $33 \%$ yeast without (A) or with (B) addition of $1500 \mu \mathrm{g} / \mathrm{ml} \mathrm{FeCl}_{3}$. At $36 \mathrm{~h}$ after hatching, cell proliferation in these tissues was monitored by BrdU labeling. The images are shown with $\times 200$ magnitude. (C, D) Midgut cells of Drosophila larvae reared in the fly diet with $33 \%$ yeast without (C) or with (D) addition of $1500 \mu \mathrm{g} / \mathrm{ml} \mathrm{FeCl}$. fect of iron in a fly diet with only $10 \%$ yeast. Under such conditions, all larvae died at the first or second-instar larval stages. However, addition of high concentrations of $\mathrm{FeCl}_{3}(500$ and $1500 \mu \mathrm{g} / \mathrm{ml})$ caused $\sim 70 \%$ of larvae surviving to third instar and $20 \%$ of larvae surviving to the pupal stage (Figure 3F), although these surviving pupae never eclosed into adults. Taken together, these results demonstrate that supplement with iron has a profound effect on growth and viability in nutrient-poor diets.

I next used the ubiquitously expressed Act-Gal4 driver to overexpress Fer2LCH and Fer1HCH simultaneously. Compared to control flies, flies with increased ferritin activity showed no significant difference in viability and body weight. Interestingly, when flies were grown in a nutrient-poor diet containing only $33 \%$ of yeast present in a normal diet, ferritin-overexpressing flies showed improved viability (by $\sim 20 \%$ ) (Figure 5A), increased body weight (by $\sim 10 \%$ for males and $\sim 15 \%$ for females) (Figure $5 \mathrm{~B}$ and $5 \mathrm{C}$ ), and a shortened period for adult emergence (by $\sim 4.5$ days, or $\sim 18 \%$ ) (Figure $5 \mathrm{D}$ ). Conversely, overexpression of a dominant-negative Fer $1 \mathrm{HCH}$, which mutates the five critical residues important for iron binding [16] (Figure 5E), led to decreased viability (by $\sim 50 \%$ ) (Figure $5 \mathrm{~A}$ ), decreased body weight (by $\sim 5 \%$ for males and $\sim 10 \%$ for females) (Figure $5 \mathrm{~B}$ and $5 \mathrm{C}$ ), and a prolonged period for adult emergence (by $\sim 1.5$ days, or $\sim 6 \%$ ) (Figure 5D). Thus, overexpression of wildtype ferritins and dominant-negative ferritins influences growth and viability in postembryonic development in a similar manner to addition of iron or iron chelators, respectively, suggesting that ferritin promotes growth and/ or antagonizes growth arrest under nutrient-poor conditions.

\section{Loss of ferritin activity leads to a starvation phenotype}

To further strengthen the hypothesis that ferritin antagonizes starvation response in nutrient-poor diets, I characterized two P-element-induced mutations in Fer2 $\mathrm{LCH}$ and one P-element-induced mutation in $\mathrm{FerlHCH}$. It is necessary to note that two of the three mutants have been previously identified [16]. These mutations behaved as null alleles since homozygotes and hemizygotes of these alleles all arrest at a similar stage (mid-first instar). The lethality of Fer2LCH or FerlHCH mutants could not be rescued by iron addition to any degree, but was completely rescued by ubiquitous expression of $\mathrm{Fer} 2 \mathrm{LCH}$ or FerlHCH, respectively. These observations are consistent with the notion that iron overload influences fly physiology by inducing ferritin expression to form ironloaded ferritin $[17,18]$.

Fer $2 \mathrm{LCH}$ or Fer $1 \mathrm{HCH}$ mutants grew to mid-first instar after hatching and then stopped growing. They were 
A

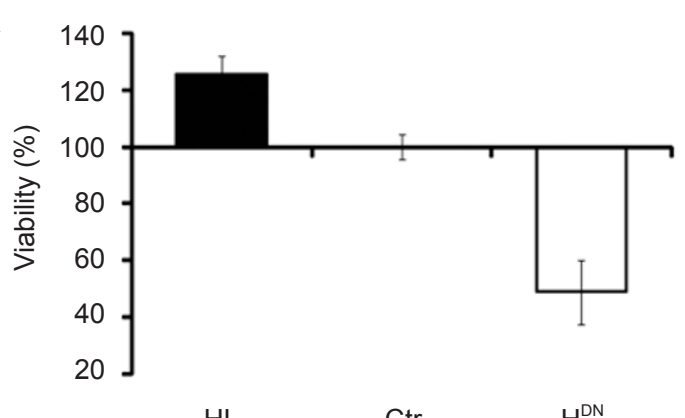

HL

C

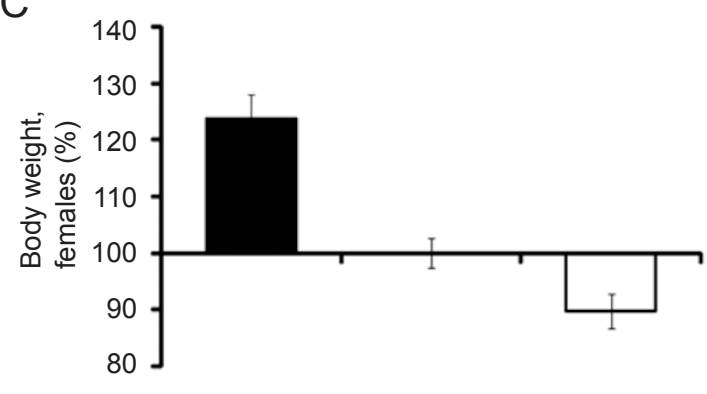

HL
B

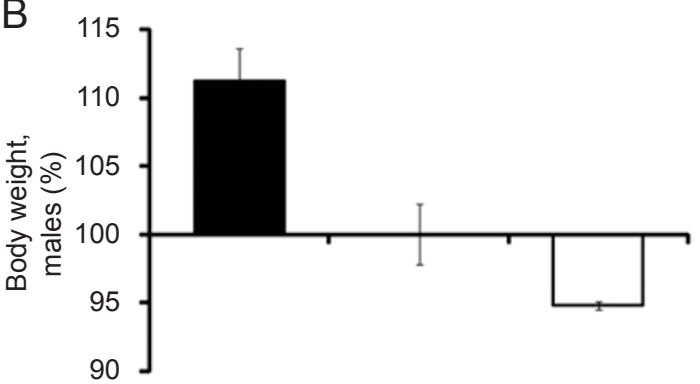

HL

Ctr

$\mathrm{H}^{\mathrm{DN}}$

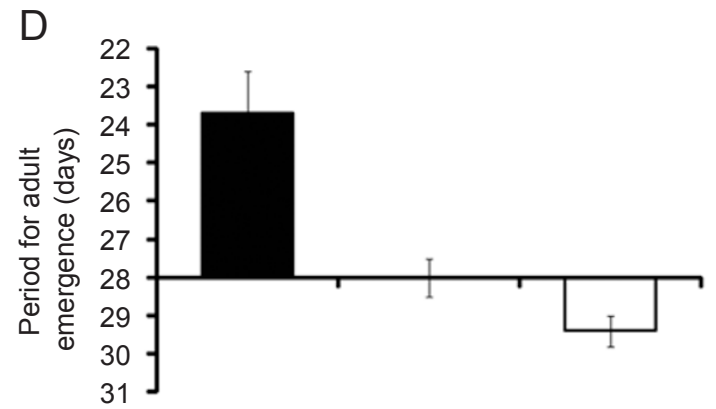

HL

Ctr

$\mathrm{H}^{\mathrm{DN}}$

$E$

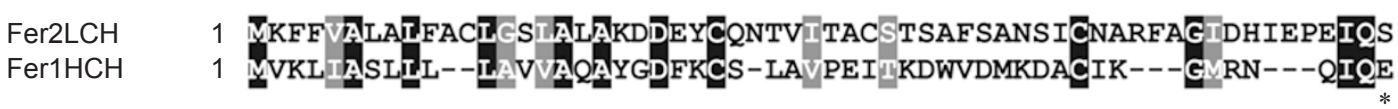
Fer2LCH 61 YINANLAKSYDYLLIATHF̄NSYQKNRPGERKYZQGLSDRSFT̄DSIATIKQVIRREGIVDF Fer1HCH 52 EINA----SYQYLAMCAYGSRDTVNRPGEAEHDFKAAKEEREHGSKLVEYLSMRGQLTIE

Fer2LCH 121 NIRHESSGSVTTKRTLEVDELHSIALALDTĒKQLATGATVHSRATHATDAEDPETAH Fer1HCH 108 VSDLINVP VAKQEWT---DGAAALSDALDLDIK-VIKSIRKLIQTCENKPYNHYH-LVD

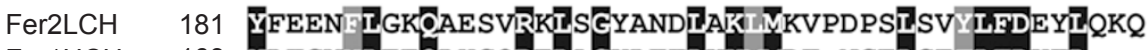

Fer1HCH 163 YLTGVYLEQLHGQRELAGKLTTLKSMYMT-NGELGE LEDKTL---

Figure 5 Ferritin stimulates Drosophila postembryonic development in nutrient-poor diets. (A-D) Effects of ferritin overexpression (Act-Gal4; UAS-Fer1HCH UAS-Fer2LCH, abbreviated as HL) and dominant-negative Fer1HCH (Act-Gal4; Fer1HCH ${ }^{\mathrm{DN}}$, abbreviated as $\mathrm{H}^{\mathrm{DN}}$ ) on viability (A), body weight of males (B) and females (C), and the period for adult emergence (D). ActGal4; + was used as a control (Ctr). The viability or the body weight of control animals was set as $100 \%$ in (B-D). (E) Alignment of Fer2 $\mathrm{LCH}$ and Fer1 HCH. Five critical amino acids of Fer1HCH, which are marked by asterisks, were mutated (E51S, Y57F, E86R, E87R, and H90D) to make a dominant-negative form of Fer1HCH.

arrested at this stage but survived for $\sim 7$ days before dying. These phenotypes are similar to those observed in starved first-instar larvae $[19,20]$. To further corroborate these findings, I examined the expression of a set of genes related to starvation response at $18 \mathrm{~h}$ after hatching, when well-fed wild-type larvae and ferritin mutant larvae had similar body sizes but starved wild-type lar- vae were $\sim 25 \%$ smaller. Compared to well-fed wild-type larvae, both starved wild-type larvae and ferritin mutant larvae showed increased expression of Scylla, Charybdis, $4 E-B P$, and Insulin Receptor (Supplementary information, Figure S2A), genes that are known to be induced by starvation $[20,21]$. In contrast, genes involved in RasMAPK, cyclin-CDK, and Hippo pathways showed little 

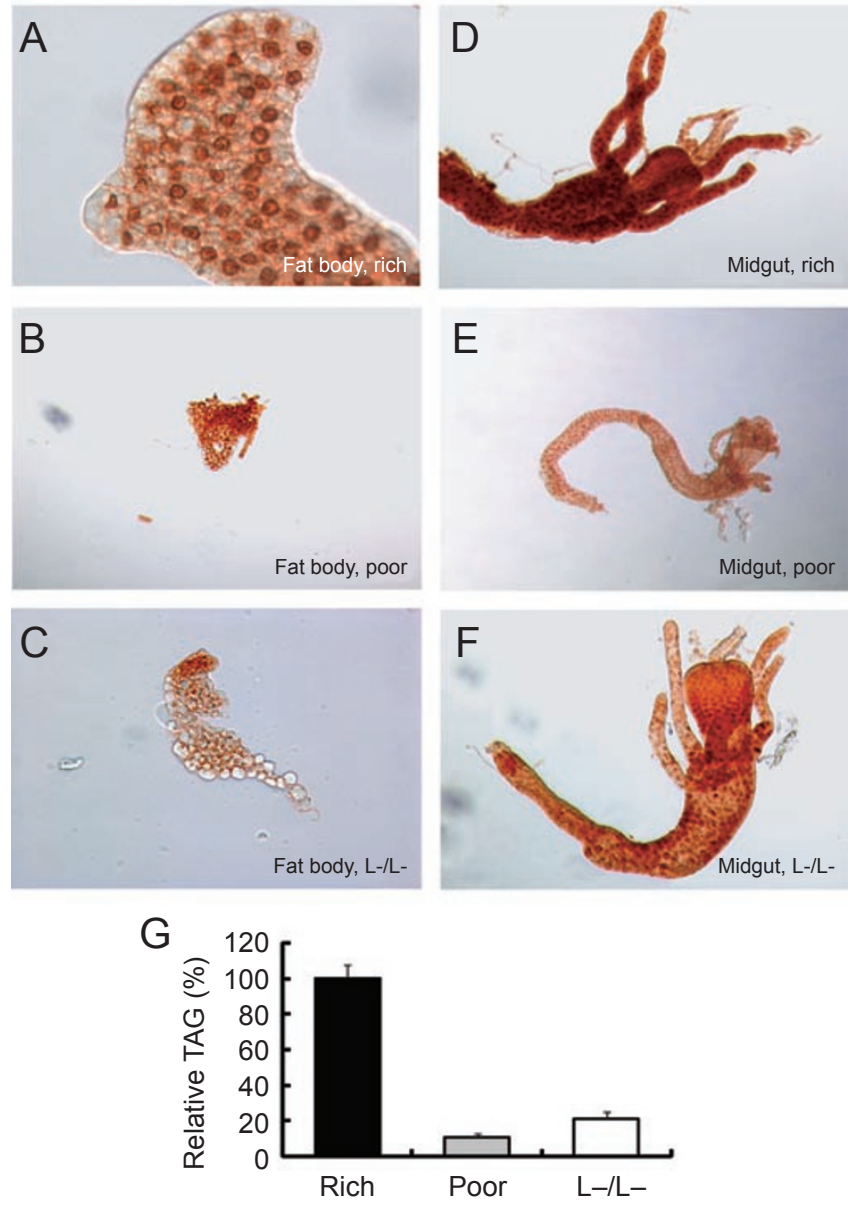

Figure 6 Loss of ferritin activity leads to diminished BrdU incorporation and decreased triacylglycerol (TAG) levels similar to those in starved wild-type larvae. (A-C) Fat body cells of larvae of well-fed wild-type (A: rich), starved wild-type (B: poor), and ferritin mutants (C: L-/L-). Eighteen hours after hatching, cell proliferation in these tissues was monitored by BrdU labeling. The images are shown with $\times 200$ magnitude. (D-F) Midgut cells of Drosophila larvae of well-fed wild-type (D: rich), starved wildtype (E: poor), and ferritin mutants (F: L-/L-). (G) TAG levels in Drosophila larvae of well-fed wild-type (rich), starved wild-type (poor), and ferritin mutants ( $L-/ L-)$.

or no changes (Supplementary information, Figure S2B). Meanwhile, at $18 \mathrm{~h}$ after hatching, both starved wildtype larvae and ferritin mutant larvae showed diminished BrdU incorporation (Figure 6A-6F) and triacylglycerol levels (Figure 6G). Thus, loss of ferritin function leads to a starvation phenotype reminiscent of that seen in starved larvae.

\section{Discussion}

It has been known for decades that the growth of ima- ginal disc cells in culture requires the addition of fly extract. In the current study, I identified iron-loaded ferritin as a growth factor for the $\mathrm{Cl} 8$ cells and my experiments of ferritin overexpression/inhibition further support a role for ferritin in regulating postembryonic development. Unlike mammalian ferritins, which are predominantly cytoplasmic iron storage proteins [14], insect ferritins are primarily secreted proteins and their protein sequences include recognizable signal peptides [13]. Thus, it has long been speculated that insect ferritins may be involved in processes beyond iron storage [22]. My identification of ferritin as a growth factor for cultured Drosophila cells supports this hypothesis. In mammals, ferritin can also be found outside of cells. It has been thought that such extracellular ferritin may play important roles via ferritin receptors under certain physiological conditions [14]. For example, serum ferritin regulates vascular remodeling and angiogenesis, suggesting a role for serum ferritin in cell proliferation [23]. Recently, two ferritin receptors, Tim-2, which binds ferritin heavy chain $[24,25]$, and Scara5, which binds ferritin light chain [26], have been identified. The mammalian ferritin receptors bind serum ferritin, stimulate its endocytosis from the cell surface with consequent iron delivery, and thus promote cell proliferation and organogenesis [23]. Unfortunately, there are no significant hits of Tim-2 and Scara5 in Drosophila and other insect genomes. The growth factor activity of ferritin described here is reminiscent of that of mammalian transferrin, which is also a secreted protein that is often supplemented as a growth factor for many mammalian cell lines [27, 28]. However, whether and how transferrin functions in maintaining iron homeostasis in insects is unclear, and a homologue of mammalian transferrin receptor is not present in Drosophila and other insect genomes $[22,29]$. Future studies will shed light on how ferritin and transferrin function in concert to maintain iron homeostasis in Drosophila and other insects.

\section{Materials and Methods}

Cell culture and bioassay for Cl8 cell growth factor activity

The IM used was Shields and Sang's M3 medium supplemented with $2 \%$ inactivated fetal bovine serum, $0.125 \mathrm{IU} / \mathrm{ml}$ insulin, and $1 \times$ penicillin-streptomycin, while the complete medium $(\mathrm{CM})$ was IM plus $2.5 \%$ fly extract [9]. Cl8 cells were maintained in CM. For bioassay, $\mathrm{Cl} 8$ cells were cultured in 24 -well plates, with $550 \mu \mathrm{l}$ of IM plus $50 \mu \mathrm{l}$ of homogenization buffer $(50 \mathrm{mM}$ Tris $+25 \mathrm{mM}$ $\mathrm{NaCl}+50$ mM EDTA $+10 \%$ sucrose $+0.1 \%$ 2-mercaptoethanol, $\mathrm{pH}$ 8.0) or FPLC buffer (control), fly extract or FPLC fractions (experimental) in each well at a seeding density of $6 \times 10^{5}$ cells/ $\mathrm{ml}$. After 4 days of incubation, the cell number in each well was counted using a hemocytometer. Activity of the $\mathrm{Cl} 8$ growth factor was calculated as fold increase with versus without fly extract (= experimental/control, mean $\pm \mathrm{SEM}, n=4$ ) or percentage of control 
(= experimental/control $\times 100$, mean $\pm \mathrm{SEM}, n=4)$.

Purification and identification of the Cl8 growth factor

Fly extract was prepared in the homogenization buffer. Freshly frozen flies were homogenized and centrifuged at $20000 \times g$ for 20 min at $4{ }^{\circ} \mathrm{C}$ to collect the supernatant, which was heated to inactivate in a $60{ }^{\circ} \mathrm{C}$ waterbath for $30 \mathrm{~min}$ and centrifuged at $20000 \times$ $g$ for $20 \mathrm{~min}$ at $4{ }^{\circ} \mathrm{C}$. The resulting supernatant was centrifuged again at $200000 \times \mathrm{g}$ for $2 \mathrm{~h}$ at $4{ }^{\circ} \mathrm{C}$ and the final supernatant was used for FPLC purification.

$1 \mathrm{ml}$ of fly extract was applied to an anion exchange column (HiTrap Q XL, $1 \mathrm{ml}$, Amersham) equilibrated with buffer A (50 $\mathrm{mM}$ Tris $+0.1 \%$ 2-mercaptoethanol, $\mathrm{pH} 8.0$ ). The column was eluted in $0-50 \%$ buffer $\mathrm{B}$ (buffer $\mathrm{A}+1 \mathrm{M} \mathrm{NaCl}$ ) over 40 min. The fractions with the highest activity from 10 separations were combined, buffer-exchanged with buffer C (20 mM MES $+10 \%$ sucrose $+0.1 \%$ 2-mercaptoethanol, $\mathrm{pH} 5.8$ ) or PBS (50 mM phosphate buffer containing $150 \mathrm{mM} \mathrm{NaCl}$ ), and concentrated to a final volume of $1 \mathrm{ml}$ using the Amicon ${ }^{\circledR}$ Ultra (MW $10 \mathrm{kDa}$ cutoff; pretreated with $1 \mathrm{mg} / \mathrm{ml}$ of BSA). A volume of $1 \mathrm{ml}$ of the above concentrated sample in buffer $\mathrm{C}$ was applied to a cation-exchange column (HiTrap SP XL, $1 \mathrm{ml}$, Amersham) equilibrated with buffer $\mathrm{C}$. The column was eluted in $0-100 \%$ buffer D (buffer $\mathrm{C}+1 \mathrm{M}$ $\mathrm{NaCl}$ ) over $20 \mathrm{~min}$. Alternatively, $1 \mathrm{ml}$ of the above concentrated sample in PBS was also separated using gel filtration (Superdex 200 HR 10/30 column, Amersham) eluted in PBS over $1 \mathrm{~h}$. The fractions defining the active zone were pooled from five strong cation-exchange or gel filtration separations and concentrated to a final volume of $1 \mathrm{ml}$ using the Amicon ${ }^{\circledR}$ Ultra. Samples containing $\mathrm{Cl} 8$ growth factor activity were separated on $12 \%$ SDS-PAGE gels, followed by Collodial Blue Staining (Invitrogen) or FASTsilver ${ }^{\mathrm{TM}}$ Gel Staining (CalBiochem). Modified porcine trypsin was used for digestion of the two SDS-PAGE-separated protein bands representing the $\mathrm{Cl} 8$ growth factor. After in-gel digestion, the peptide mixture was dissolved and injected into reversed phase nanoHPLC/ion trap mass spectrometry instruments with a nanospray source. The resulting files were searched against NCBI-nr protein sequence databases. The LC-MS analysis was performed using the Mass Spectrometry facility at the University of Texas Southwestern Medical Center in Dallas.

\section{Drosophila culture}

Standard Drosophila diet contains corn meal $(67.5 \mathrm{~g} / \mathrm{l})$, molasses $(90 \mathrm{ml} / \mathrm{l})$, agar $(12.2 \mathrm{~g} / \mathrm{l})$, and $16.8 \mathrm{~g} / 1$ yeast. The fly food used in the starvation experiments contained $5.6 \mathrm{~g} / 1$ (33\%) or $1.68 \mathrm{~g} / 1$ $(10 \%)$ yeast. To determine the effects of iron and iron chelator on Drosophila postembryonic development, 5, 50, 150, 500, and 1500 $\mu \mathrm{g} / \mathrm{ml} \mathrm{FeCl}_{3}$, or $0.02,0.2$, and $2 \mathrm{mM}$ desferrioxamine were added to fly diets. Fifty newly hatched larvae were fed in a vial containing $10 \mathrm{ml}$ of fly diet. The larvae were incubated at $25{ }^{\circ} \mathrm{C}, \sim 50 \%$ humidity, and a 12-h light/dark cycle. Thirty vials were used for each condition. Newly emerged flies were collected each day and male and female adults separated. For measuring the duration of postembryonic development (i.e., the time period from hatching to adult emergence), the newly eclosed flies of each day were normalized to the total number of eclosed adult flies. $\mathrm{AE}_{50}$ represents the time point with $50 \%$ of adult emergence. Viability = total number of eclosed adult flies $/ 50 \times 100$. Body weight was measured using $\mathrm{d} 2$ male and female adults. Statistical analysis was done using Student's $T$-test and ANOVA. For larval starvation, newly hatched larvae were transferred to $20 \%$ sucrose in PBS for $18 \mathrm{~h}$.

\section{BrdU labeling and quantitative real-time PCR}

BrdU labeling in Drosophila larval organs was carried out as described in [19] with slight modification. After dissection, larvae tissues were incubated in $100 \mu \mathrm{g} / \mathrm{ml} \mathrm{BrdU}$ in PBS for $30 \mathrm{~min}$ and fixed in 5\% formaldehyde for $45 \mathrm{~min}$. After denaturing DNA, the tissues were incubated in anti-BrdU primary antibody $(1: 100)$ for $2 \mathrm{~h}$ and HRP-coupled goat anti-mouse secondary antibody $(1: 200)$ for $2 \mathrm{~h}$. The reaction was developed in DAB staining solution and observed in a ZEISS Axionvert 25 microscope.

For quantitative real-time PCR, total RNA was extracted from first-instar larvae of a given genotype/treatment. First-strand cDNA was synthesized from $1 \mu \mathrm{g}$ of total RNA in $20 \mu \mathrm{l}$ of reaction mixture including reverse transcriptase XL and oligo dT18. For each real-time PCR reaction, $10 \mu \mathrm{l}$ of $\mathrm{SYBR}^{\circledR}$ Green PCR Master Mix, $2 \mu \mathrm{l}$ of the first-strand cDNA (equal to $0.1 \mu \mathrm{g}$ of total RNA), and $1 \mu \mathrm{M}$ of a pair of primers for each gene were used. PCR was performed by a Rotor-Gene 2000 thermocycler under the following conditions: $94{ }^{\circ} \mathrm{C}$ for $1 \mathrm{~min}$; 40 cycles of $94{ }^{\circ} \mathrm{C}$ for $5 \mathrm{~s} ; 55^{\circ} \mathrm{C}$ for $15 \mathrm{~s}$; and $72{ }^{\circ} \mathrm{C}$ for $15 \mathrm{~s}$. The relative transcripts of the 20 genes were calculated with threshold cycle and the standard curves. Their expression levels were normalized with rp49 [30].

\section{Drosophila genetics}

An Act-Gal4 driver on the second chromosome was used to ubiquitously expressed ferritin subunits. Multiple UAS-Fer1HCH and UAS-Fer2LCH lines were generated using the same procedure as shown in [17]. UAS-Fer1HCH UAS-Fer2LCH (HL) lines were generated by meiotic recombination of UAS-Fer1HCH and UASFer2LCH insertions on the second chromosome. Dominant-negative ferritin was generated by mutating five critical amino acids of Fer1HCH involved in iron binding $\left(\mathrm{H}^{\mathrm{DN}}\right)$ [18]. The mutations are E51S, Y57F, E86R, E87R, and H90D (Figure 5E). Multiple transgenic lines were tested and showed similar effects.

$D f(3 R) t l l-g$ was used as a deficiency that uncovers Fer $2 L C H$ and $\mathrm{Fer} 1 \mathrm{HCH}$. P-element alleles of ferritin subunits were obtained from Bloomington Drosophila Stock Center. The Fer $2 \mathrm{LCH}$ mutants were Fer $2 L_{C H} H^{\text {neo60 }}$ and Fer $2 L C H^{00035}$. The Fer $1 H C H$ mutant was $F$ er $1 H_{C H} H^{00451}$. They were balanced with a GFP-containing TM3 balancer to determine their lethality.

\section{Acknowledgment}

This study was supported by 2007CB947100, 2006CB943902, 30870299, KSCX-YW-N-009 and Hundred Talent Project to SL. Part of the work was conducted in Dr Duojia Pan's lab in the Department of Molecular Biology and Genetics, Howard Hughes Medical Institute, Johns Hopkins University School of Medicine. SL sincerely thanks Dr Pan for all his guidance and help in designing and performing the experiments as well as writing the manuscript.

\section{References}

1 Barnes D, Sato G. Methods for growth of cultured cells in serum-free medium. Anal Biochem 1980; 102:255-270.

2 Barnes D. Nutritional and hormonal requirements of mammalian cells in culture. World Rev Nutr Diet 1985; 45:167-197. 
3 Bryant PJ. Pattern formation in imaginal discs. In: Ashburner M, Wright TRF, eds. The Genetics and Biology of Drosophila. London: Academic Press, 1985:230-336.

4 Cohen SM. Imaginal disc development. In: Bate M, Arias AM, eds. The Development of Drosophila melanogaster. Cold Spring Harbor: Cold Spring Harbor Laboratory Press, 1993:747-841.

5 Diaz-Benjumea FJ, García-Bellido A. Behavior of cells mutant for an EGF receptor homologue of Drosophila in genetic mosaics. Proc R Soc Lond B 1990; 242:36-44.

6 Chen C, Jack J, Garofalo RS. The Drosophila insulin receptor is required for normal growth. Endocrinology 1996; 137:846856.

7 Johnston LA, Edgar BA. Wingless and Notch regulate cellcycle arrest in the developing Drosophila wing. Nature 1998; 394:82-84.

8 Echalier G. Drosophila Cells in Culture. London: Academic Press, 1997.

9 Currie DA, Milner MJ, Evans CW. The growth and differentiation in vitro of leg and wing imaginal discs cells from Drosophila melanogaster. Development 1988; 102:805-814.

10 Cullen CF, Milner MJ. Parameters of growth in primary cultures and cell lines established from Drosophila imaginal discs. Tissue Cell 1991; 23:29-39.

11 Kawamura K, Shibata T, Saget O, Peel D, Bryant PJ. A new family of growth factors produced by the fat body and active on Drosophila imaginal disc cells. Development 1999; 126:211-219.

12 Zurovec M, Dolezal T, Gazi M, Pavlova E, Bryant PJ. Adenosine deaminase-related growth factors stimulate cell proliferation in Drosophila by depleting extracellular adenosine. Proc Natl Aca Sci USA 2002; 99:4403-4408.

13 Dunkov BC, Georgieva T. Organization of the ferritin genes in Drosophila melanogaster. DNA Cell Biol 1999; 18:937944.

14 Theil EC. Iron, ferritin, and nutrition. Annu Rev Nutr 2004; 24:327-343.

15 Bakker GR, Boyer RF. Iron incorporation into apoferritin: the role of apoferritin as a peroxidase. J Biol Chem 1986; 261:13182-13185.

16 Georgieva T, Dunkov BC, Harizanova N, Ralchev K, Law $\mathrm{JH}$. Iron availability dramatically alters the distribution of ferritin subunit messages in Drosophila melanogaster. Proc Natl Acad Sci USA 1999; 96:2716-2721.

17 Missirlis F, Kosmidis S, Brody T, et al. Homeostatic mechanisms for iron storage revealed by genetic manipulations and live imaging of Drosophila ferritin. Genetics 2007; 177:89100 .

18 Georgieva T, Dunkov BC, Dimov S, Ralchev K, Law JH. Drosophila melanogaster ferritin: cDNA encoding a light chain homologue, temporal and tissue specific expression of both subunit types. Insect Biochem Mol Biol 2002; 32:295302.

19 Briton JS, Edgar BA. Environment control of the cell cycle in Drosophila: nutrition activates mitotic and endoreplicative cells by distinct mechanisms. Development 1999; 125:21492158.

20 Zinke I, Schutz CS, Katzenberger JD, Bauer M, Pankratz MJ. Nutrient control of gene expression in Drosophila microarray analysis of starvation and sugar-dependent response. EMBOJ 2002; 21:6162-6173.

21 Reiling JH, Hafen E. The hypoxia-induced paralogs Scylla and Charybdis inhibit growth by down-regulating S6K activity upstream of TSC in Drosophila. Genes Dev 2004; 18:28792892.

22 Nichol H, Law JH, Winzerling JJ. Iron metabolism in insects. Annu Rev Entomol 2002; 47:535-559.

23 Coffman LG, Parsonage D, D’Agostino R, Torti FM, Torti SV. Regulatory effects of ferritin on angiogenesis. Proc Natl Acad Sci USA 2009; 106:570-575.

24 Chen TT, Li L, Cheng DH, et al. TIM-2 is expressed on B cells and in liver and kidney and is a receptor for $\mathrm{H}$-ferritin endocytosis. J Exp Med 2005; 202:955-965.

25 Todorich B, Zhang X, Slagle-Webb B, Seaman WE, Conner JR. Tim-2 is the receptor for H-ferritin on oligodendrocytes. $J$ Neurochem 2008; 107:1495-1505.

26 Li JY, Paragas N, Ned RM, et al. Scara5 is a ferritin receptor mediating non-transferrin iron delivery. Dev Cell 2009; 16:3546.

27 Hayashi I, Sato GH. Replacement of serum by hormones permits growth of cells in a defined medium. Nature 1975; 259:132-134.

28 Rossi MC, Zetter BR. Selective stimulation of prostatic carcinoma cell proliferation by transferrin. Proc Natl Acad Sci USA 1992; 89:6197-6201.

29 Dunkov BC, Georgieva T. Insect iron binding proteins: insights from the genomes. Insect Biochem Mol Biol 2006; 36:300-309.

30 Liu Y, Sheng Z, Liu H, et al. Juvenile hormone counteracts the bHLH-PAS transcriptional factor MET and GCE to prevent caspase-dependent programmed cell death in Drosophila. Development 2009; 136:2015-2025.

(Supplementary information is linked to the online version of the paper on Cell Research website.) 